\title{
Much ado over the new South African PMTCT guidelines
}

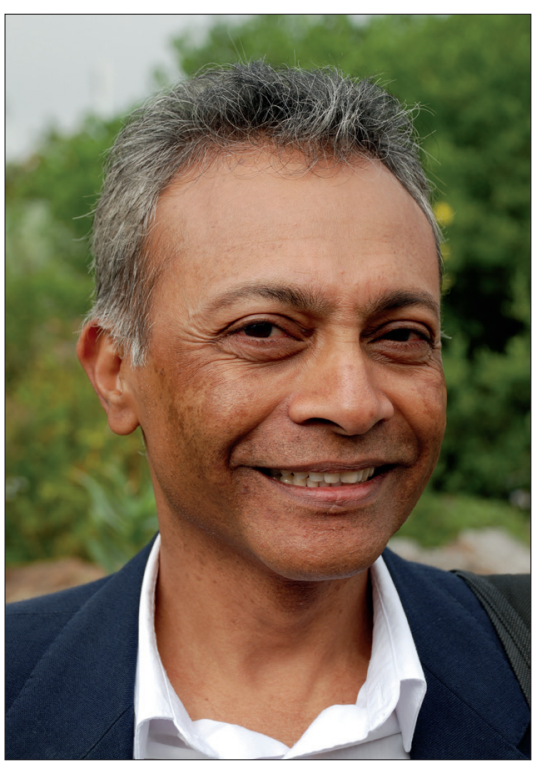

Deputy Director of Health, Dr Yogan Pillay.

A group of well-respected South African academics and HIV experts have started a national debate by questioning the 'dangerously hasty' acceptance and implementation of lifelong antiretroviral therapy (ART) for HIV-positive pregnant women in resource-constrained settings.

The South African National Department of Health will introduce updated prevention of mother-to-child transmission (PMTCT) guidelines this month, based in part on the World Health Organization (WHO)'s recommendations on the use of ART for treating pregnant women and preventing HIV infection in infants. The guideline update will recommend a standardised triple-drug regimen to treat HIV-infected pregnant women (regardless of CD4 count) during pregnancy and breastfeeding, with continuation of ART after breastfeeding for women with $\mathrm{CD} 4$ counts less than 350 (Option B). HIV-exposed infants will receive nevirapine prophylaxis for $4-6$ weeks and should be tested for HIV at 6 weeks of age. The new treatment guidelines are expected to further enhance the success of the PMTCT programme in South Africa (HIV transmission from mother to child is down from $8.0-20.2 \%$ prior to 2007 , to $3.5 \%$ in 2010), with the goal being the complete elimination of preventable HIV infection in infants. More critically, it will bolster a concerted effort to reduce high maternal morbidity and mortality figures; HIV, complicated by accompanying infections such as tuberculosis, pneumonia and meningitis, is responsible for $40 \%$ of maternal deaths in South Africa. Further guidance on treatment options for pregnant women, including a stronger recommendation to offer all pregnant women lifelong ART irrespective of $\mathrm{CD} 4$ count (Option $\mathrm{B}+$ ) is expected in the form of revised $\mathrm{WHO}$ guidelines in June.

The authors conclude that 'advocacy is crucial, and reliance only on what has been scientifically proven would result in slow progress.

However, with so many unknowns, the strong push for countries to switch to $B+$ is premature ... and dangerous.' 
Table 1. Three options for PMTCT programmes

\begin{tabular}{|c|c|c|c|}
\hline & \multicolumn{2}{|c|}{ Woman receives } & \multirow[b]{2}{*}{ Infant receives: } \\
\hline & $\begin{array}{c}\text { Treatment } \\
\text { (for CD4 count } \\
\leq 350 \text { cells/mm } / \mathrm{mm}^{3} \text { ) }\end{array}$ & $\begin{array}{c}\text { Prophylaxis } \\
\text { (for CD4 count } \\
\leq 350 \text { cells } / \mathrm{mm}^{3} \text { ) }\end{array}$ & \\
\hline Option Aa & $\begin{array}{l}\text { Triple ARVs starting } \\
\text { as soon as diagnosed, } \\
\text { continued for life }\end{array}$ & $\begin{array}{l}\text { Antepartum: AZT starting as } \\
\text { early as } 14 \text { weeks' gestation } \\
\text { Intrapartum: at onset of } \\
\text { labour, sdNVP and first } \\
\text { dose of AZT/3TC } \\
\text { Postpartum: daily AZT/3TC } \\
\text { through } 7 \text { days postpartum }\end{array}$ & $\begin{array}{l}\text { Daily NVP from birth } \\
\text { through } 1 \text { week beyond } \\
\text { complete cessation of } \\
\text { breastfeeding; or, if not } \\
\text { breastfeeding or if mother } \\
\text { is on treatment, through } \\
\text { age } 4 \text { - } 6 \text { weeks }\end{array}$ \\
\hline \multirow[t]{2}{*}{ Option Ba } & \multicolumn{2}{|c|}{ Same initial ARVs for both ${ }^{\mathrm{b}}$ : } & \multirow{2}{*}{$\begin{array}{l}\text { Daily NVP or AZT from } \\
\text { birth through age } 4 \text { - } 6 \\
\text { weeks regardless of } \\
\text { infant feeding method }\end{array}$} \\
\hline & $\begin{array}{l}\text { Triple ARVs starting } \\
\text { as soon as diagnosed, } \\
\text { continued for life }\end{array}$ & $\begin{array}{l}\text { Triple ARVs starting as early } \\
\text { as } 14 \text { weeks gestation and } \\
\text { continued intrapartum and } \\
\text { through childbirth if not } \\
\text { breastfeeding or untill } 1 \\
\text { week after cessation of all } \\
\text { breastfeeding }\end{array}$ & \\
\hline \multirow[t]{2}{*}{ Option B+ } & \multicolumn{2}{|c|}{ Same for treatment and prophylaxis ${ }^{b}$} & \multirow{2}{*}{$\begin{array}{l}\text { Daily NVP or AZT from } \\
\text { birth through age } 4 \text { - } 6 \\
\text { weeks regardless of } \\
\text { infant feeding method }\end{array}$} \\
\hline & \multicolumn{2}{|c|}{$\begin{array}{l}\text { Regardless of CD4 count, triple ARVs starting as soon as } \\
\text { diagnosed, }{ }^{C} \text { continued for life }\end{array}$} & \\
\hline
\end{tabular}

Note: "Triple ARVs" refers to the use of one of the recommended 3-drug fully suppressive treatment options. a Recommended in WHO 2010 PMTCT guidelines.

True only for EFV-based first-line ART; NVP-based ART not recommended for prophylaxis (CD >350).

Formal recommendations for Option B+ have not been made, but presumably ART would start at diagnosis.

Source: World Health Organization (WHO).

According to National Deputy Director General of Health, Dr Yogan Pillay, the new PMTCT guidelines will be supported by 90 teams of trainers that will up-skill 10000 public sector HIV healthcare workers (mainly nurses) at 3000 facilities by 23 March this year. Another critical element, the supply of ART, is being sourced from 3 different suppliers, and the Department of Health is confident that adequate stocks of medications will be ensured. National Minister of Health, Dr Aaron Motsoaledi, announced on 29 November last year that his negotiators had slashed R2.2 billion off the latest 2-year ART tender, which includes the lowest-cost fixed-dose combination (FDC) ART; pregnant women will be a priority group to receive FDCs, simplifying the implementation of the new guidelines. Pillay told Izindaba that the decision to update the 2010 PMTCT guidelines was based on the advice of 'our best scientists,' confirming his earlier comments at the inaugural Southern African HIV Clinician's Society Conference in Cape Town in November last year that the government was basing its decision on the best science available and would not be 'bullied' into riskier options.

These plans were preceded by a commentary on adoption of PMTCT treatment options in the 26 January 2013 edition of the international journal the Lancet. In the article, South African researchers Hoosen Coovadia, Anna
Coutsoudis, Ameena Goga, Chris Desmond, Peter Barron and Vivian Black expressed concern about the 'single-minded advocacy' behind what they labeled 'the extreme' PMTCT Option B+ by some organisations and international agencies with 'so little consultation, debate and discussion.' The tone of the Lancet commentary surprised many clinicians working with HIV in South Africa's public sector. Several HIV clinicians working at the coalface told Izindaba they encounter programmatic weaknesses with the current PMTCT guidelines (Option A), such as inefficient support of women on AZT prophylaxis during pregnancy, and difficulties in the consistent use of nevirapine prophylaxis for infants; to them, the PMTCT guideline update is a welcome solution that is worth the additional resources required.

\section{PMTCT guideline update concerns}

The local academics say in their Lancet commentary that, ethically, Option $\mathrm{B}+$ prioritises women over men, could create community tensions over unequal access (owing to the different treatment thresholds), and raise questions over the lifelong treatment of women who may not understand the long-term costs and benefits. Medically, they question the benefits of Option B+ on long-term HIV-free survival: the potential for drug resistance (through lack of adherence), and whether there is sufficient evidence to back the suggestion that pregnant women and new mothers are a risk group who have discordant relationships and thus contribute to ongoing transmission. As a programme, they doubt whether Option $\mathrm{B}+$ implementation can be successful in resource-constrained settings and worry that it will divert resources away from both universal HIV access and other chronic and infectious diseases. Economically, they question the 'assumption' that economies of scope will favour the 3-in-1 intervention of PMTCT, treatment, and 'treatment as prevention.' They suggest that potential low retention rates could render the economic argument invalid. The authors conclude that 'advocacy is crucial, and reliance only on what has been scientifically proven would result in slow progress. However, with so many unknowns, the strong push for countries to switch to $\mathrm{B}+$ is premature.... and dangerous.

Implementation of Options B or B+ will compromise the PROMISE (Promoting Maternal Infant Survival Everywhere) trial, a global multi-site study (United States, South America, Asia and 7 sub-Saharan countries) researching the best antepartum and postpartum regimens for PMTCT. In a footnote to the Lancet commentary, Professor Coutsoudis is cited as a member of the protocol team of the PROMISE study. The authors collectively declared no conflict of interest.

\section{The WHO says Option B+ has 'important advantages' (if viral suppression is maintained) over options $A$ and $B$, but needs 'evaluation in programme and field settings.'}

\section{PMTCT guideline update benefits}

Dr. Vivian Cox, Médecins Sans Frontieres (MSF) Deputy Medical Field Coordinator for Khayelitsha, says 'the use of ART for all pregnant women regardless of $\mathrm{CD} 4$ count has the potential to reduce the risk of common opportunistic infections in pregnancy - tuberculosis, cryptococcal meningitis, and PCP pneumonia - and contribute to the reduction of maternal mortality in South Africa, dovetailing neatly with both Millennium Development and National Department of Health goals. MSF has emphasised the need for mentorship of antenatal care nurses and midwives to initiate ART in pregnant women in Khayelitsha, both 
to address the programmatic implementation of the new PMTCT guidelines, and to meet South Africa's National Strategic Plan goal of $85 \%$ of all ART treatment initiations to be done by nurses by 2015. Cox noted that 'a balance of waiting for clinical trial evidence and the need for implementation of ART for pregnant women regardless of CD4 count can be achieved through pilot projects and operational research' during the early phases of guideline implementation. The support of such pilots can 'include strengthening critical components of maternal child health, such as family planning and early presentation to antenatal care.' Malawi's experience with Option $\mathrm{B}+$, which has greatly increased ART coverage but faced difficulties with adherence and linkages to care after delivery, ${ }^{[1]}$ highlights areas that South African PMTCT programmes will need to focus on as the guideline updates are put into practice.

\section{HIV, complicated by accompanying infections such as tuberculosis, pneumonia and meningitis, is responsible for $40 \%$ of maternal deaths in South Africa.}

Contrary to the claims that governments are pressured into early implementation by international agencies, the South African government has the support of an 'extremely strong scientific community' that works closely with the Department of Health, Cox said. Dr Rosie Burton, an infectious diseases specialist, and Dr Janet Giddy, a PMTCT
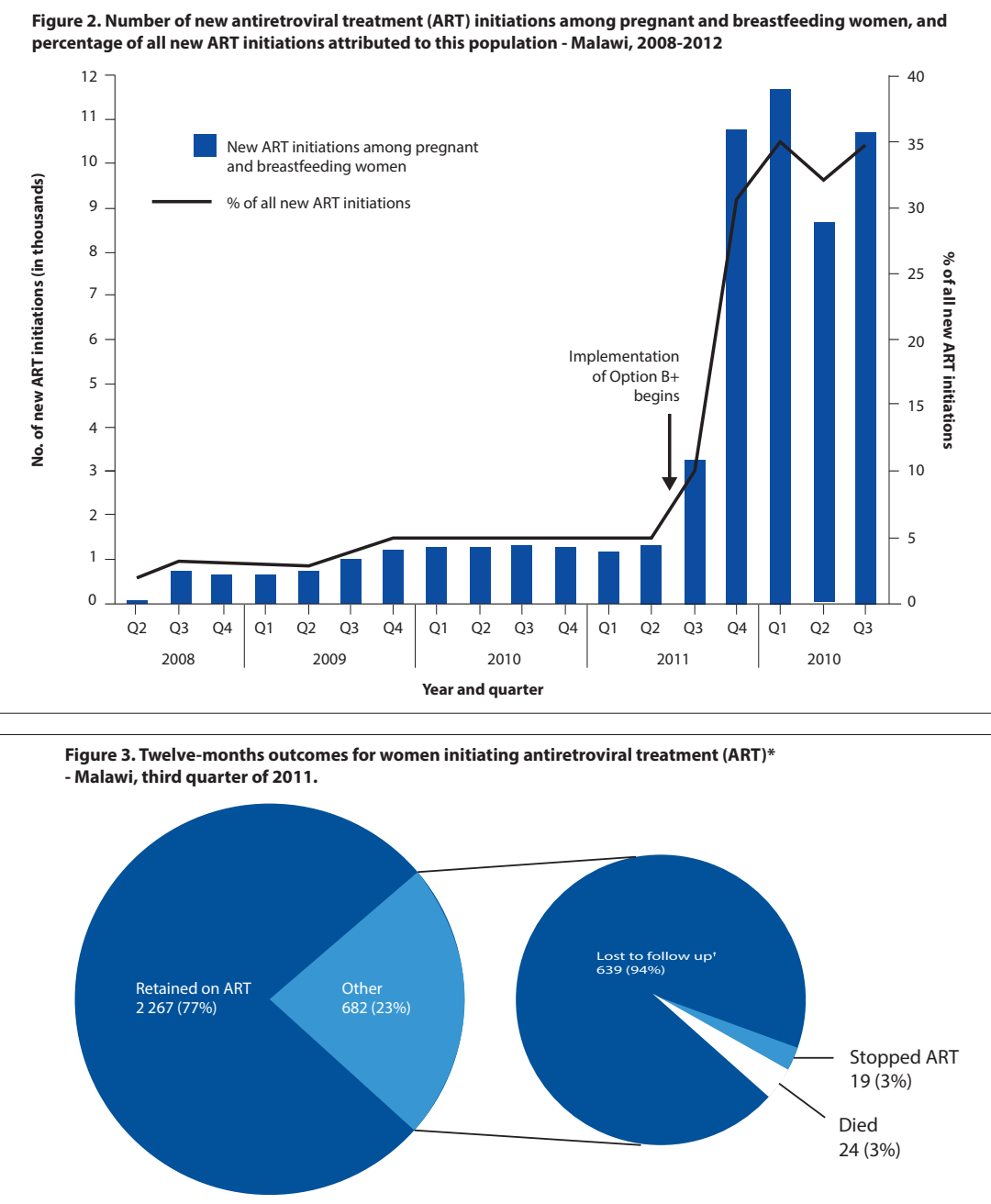

${ }^{*} \mathrm{~N}=2$ 949. A total of 3241 women initiated ART in the third quarter of 2011. However, 315 women were excluded from this analysis because they were documented to have transferred care from the clinic where they were initiated on ART and outcomes could not be verified. An additional 23 women were excluded because of incomplete information regarding the reason for starting ART.

† Some women labelled as lost to follow-up might be deceased 12 months after initiating ART.

Source of Figs 2 and 3: Morbidity and Mortality Weekly Report, Vol 62(8) $)^{[2]}$ clinician and pioneer of the now defunct but innovative Sinikithemba HIV/AIDS programme at McCord Hospital, scotched fears of creating community tensions (via different treatment thresholds that might discriminate against men and other groups) with Option B+. 'There were no community protests when the $\mathrm{CD} 4$ threshhold was raised to 350 for pregnant women, before being raised for the general population, or when women had access to HIV testing at antenatal clinics - except for the stigma, Burton countered. Both said many people would agree that treating a pregnant woman as 'special' was appropriate, given that the health and survival of herself and her unborn child (and other children affected by the mother's health) were inextricably linked. ART cessation after breastfeeding has the potential to create confusing messages to the community about stopping ART after the commitment to start, and prior research has shown an increase in mortality in patients who undergo scheduled treatment interruptions. Therefore Drs Giddy, Burton and Cox strongly recommended that women should be able to choose themselves whether to continue ART after breastfeeding ('Optional $\mathrm{B}+$ '); this would identify those with the most motivation and thererfore likely good longterm adherence and retention in care.

\section{WHO advice}

The WHO says Option B+ has 'important advantages' (if viral suppression is maintained) over options A and B, but needs 'evaluation in programme and field settings.' Although South Africa has chosen not to implement Option $\mathrm{B}+$, the programmatic advice has implications for the PMTCT guidelines; it lists the advantages as including:

1. Further simplification of PMTCT programme requirements - no need for CD4 testing to determine ART eligibility (as required in Option A) or whether ART should be stopped or continued after the risk of mother-to-child transmission has ceased (as in Option B). CD4 counts or viral load assays are still desirable for determining baseline immunological status and monitoring response to treatment.

2. Extended protection from mother-tochild transmission in future pregnancies from the time of conception.

3. A strong and continuing prevention benefit against sexual transmission in serodiscordant couples and partners.

4. Probable benefit to the woman's health of earlier treatment and avoiding the risks of stopping and starting triple ARVs, especially in settings with high fertility. 
5. A simple message to communities that, once ART is started, it is taken for life.

The WHO guidance includes concerns about potential 'important programmatic, operational and clinical challenges.' Examples are service organisation and service delivery of ART in maternal child health and primary care settings; cost and sustainability; ARV adherence and retention in care; referral mechanisms and transitions from the PMTCT programme to HIV care and treatment programmes; concerns about HIV drug resistance with long-term use of ART when initiated in early HIV disease; safety of increased ARV exposure for the fetus/infant; acceptability; and equity. The WHO advises countries implementing Option $\mathrm{B}$ or $\mathrm{B}+$ or planning demonstration projects to 'monitor this approach closely to address these issues and assess the feasibility, cost-benefit and public health impact of Option B or
$\mathrm{B}+$.' The WHO's latest programmatic update concludes: 'this is an appropriate time for countries to start assessing their situation and experience to make optimal programmatic choices.'

From the robust debate that the Lancet article has generated locally, it would seem this is happening in South Africa ...

\section{Chris Bateman}

chrisb@hmpg.co.za

1. Coutsidis A, Goga A, Desmond C, Barron P, Black V, Coovadia H. Is Option B+ the best choice? Lancet 2013;381(9863):269 - 271. [http://dx.doi.org/10.1016/S0140-6736(12)61807-8]

2. Impact of an innovative approach to prevent mother-to-child transmission of HIV - Malawi, July 2011 - September 2012. Morb Mortal Wkly Rep 2013;62(8):148-151.

S Afr Med J 2013;103(4):218-221.

DOI: $10.7196 / 6880$ 